\title{
EL CONCEPTO DE ACUMULACIÓN CIVILIZATORIA. ENTRE UNIVERSALISMO E IDENTIDAD CULTURAL*
}

\author{
Ernesto Ottone \\ Universidad Diego Portales
}

\begin{abstract}
Resumen: Frente al problema de si el Estado laico, la democracia y los derechos humanos deben convertirse en la medida universal de civilización o si, por el contrario, debemos dejar que prevalezca la identidad cultural que cada nación o grupo humano quiera defender para sí mismo, el autor de este ensayo postula que una y otra cosa son abstracciones rígidas, que la historia ha demostrado que ni el universalismo ni la identidad cultural poseen una forma inamovible. Ambas son permeables y se debe tener en cuenta esta realidad cuando se estén buscando las formas de un mundo más civilizado.

Palabras Clave: Occidente, derechos universales, modernidad, cosmopolitismo, identidad cultural.
\end{abstract}

\footnotetext{
ERnesto Ottone. Sociólogo y doctor en ciencias políticas por Universidad de París III, La Sorbonne Nouvelle. Profesor titular en la Universidad Diego Portales y profesor adjunto en la Universidad de Chile. Email: ernesto.ottone@udp.cl.

* Versión abreviada de la ponencia realizada por el autor con ocasión de su ingreso como miembro de número a la Academia de Ciencias Sociales, Políticas y Morales del Instituto de Chile.
} 


\title{
THE CONCEPT OF CIVILIZATIONAL ACCRETION. BETWEEN UNIVERSALISM AND CULTURAL IDENTITY
}

\begin{abstract}
AвSTRACt: Addressing the problem of whether the secular State, democracy and human rights should become the universal measure of civilization or whether, conversely, the cultural identity that each nation or human group wishes to uphold for itself should be allowed to prevail, the author of this essay argues that both of these are rigid abstractions, with history showing that neither universalism nor cultural identity possesses an unchanging form, but that both are permeable. This fact should be borne in mind in the search for the forms of a more civilized world.
\end{abstract}

KEYWORD: West, universal rights, modernity, cosmopolitanism, cultural identity.

\footnotetext{
Eisten buenas razones para considerar el siglo $\mathrm{XX}$ como un siglo corto.
}

Hacia los años ochenta se producen modificaciones de una magnitud inesperada. Un cambio tecnológico profundo, particularmente en las comunicaciones, constituye la base de la contracción del espacio y el tiempo en los cuales se desarrolla la vida de las sociedades, la política y la economía. Se produce una transición veloz desde la sociedad industrial a la sociedad de la información, como la denomina Castells, la modernidad baja según Touraine, la sociedad del riesgo de acuerdo a Beck o los tiempos líquidos en palabras de Bauman.

Esa nueva realidad marcó entre 1985 y 1992 la caída del orden político internacional surgido de la Segunda Guerra Mundial, el de la Guerra Fría, caracterizado por una estructura bipolar en la cual dos superpotencias, que representaban proyectos de sociedades contrapuestas, se disputaban la hegemonía mundial a través de conflictos y negociación de esos conflictos, deslocalizando los enfrentamientos y dándoles un significado ideológico más allá, en ocasiones, de sus causalidades más profundas.

Como señaló con agudeza Medina Echavarría:

[Existía] una situación en la que, como en la duradera estratificación del Ancien Régime, todos conocen exactamente el puesto que les corresponde y que de hecho ocupan. Todas las formas de conducta interna y externa, nacional o internacional sólo existen y son comprendidas en función del antagonismo fatalmente plan- 
teado. Hasta el punto en que, cuando en ciertos años algunos se definen como no alineados, no necesitan declarar su sentido ni preguntarse en qué consiste el abandono de la fila. ${ }^{1}$

Pese a todos sus avatares y grietas crecientes, ese orden parecía una realidad difícil de remover. Nadie previó que terminaría inesperadamente por el desmoronamiento de una de sus partes, la Unión Soviética, y con ello su estructura imperial, creando un estupor interpretativo que se constituyó en un nuevo llamado a la humildad de las ciencias sociales y su anoréxica capacidad predictiva.

De las muchas interpretaciones con relación a cómo se organizaría el orden internacional a posteriori, dos de ellas alcanzaron gran difusión.

La visión optimista, enmarcada en la idea del progreso de la Ilustración, se cristalizó de manera un tanto rústica en la visión de inspiración hegeliana y kojeviana de Francis Fukuyama en El fin de la historia y el último hombre, ${ }^{2}$ quien vio en el fin de la Guerra Fría el triunfo definitivo de la economía de mercado y la democracia liberal, un arribo definitivo a un mundo post-dialéctico, aquel que para Hegel se encarnaba en el Estado moderno racional y para Marx, en la desaparición del Estado y la llegada del comunismo. En este mundo armónico terminaba la historia entendida como una dialéctica de avances conflictivos y donde sólo quedarían guerras de retaguardia destinadas a desaparecer. El futuro sería el imperio de la razón.

La vida le hizo después reconocer la candidez de su análisis.

Desde una tradición más pesimista y conservadora Samuel Huntington, en su Choque de civilizaciones, ${ }^{3}$ pensaba que la historia guerrera continuaría y se ahondaría a través de conflictos más duros e irreductibles a través de la guerra de las civilizaciones. Su pensamiento muestra una matriz analítica emparentada con el pensamiento de Oswald Spengler, pero aún más de Arnold Toynbee.

${ }^{1}$ José Medina Echavarría, "América Latina en los escenarios posibles de la distensión", Revista de la Cepal 2 (1976).

${ }^{2}$ Francis Fukuyama, The End of History and the Last Man (Nueva York: The Free Press, 1992).

${ }^{3}$ Samuel P. Huntington, The Clash of Civilizations and the Remaking of World Order (Nueva York: Simon \& Schuster, 1996). 
Él liga su concepto de civilizaciones a espacios culturales marcados sobre todo por el factor religioso, y los concibe como realidades extremadamente compactas llamadas a defender y propagar sus principios, lo que por cierto no augura un porvenir pacífico.

Si analizamos lo sucedido desde entonces, esta visión aparecería más apegada a la realidad. Pero ello es sólo a primera vista: el campo de conflictos ha sido mucho más complejo.

La ausencia de un orden internacional tan estructurado como el anterior no ha sido ni más ni menos deseable que el orden de la Guerra Fría. Sí ha adquirido otras características: nuevos tipos de conflicto, nuevos actores, nueva base tecnológica, nuevas alianzas y nuevas enemistades, pero nada como para sentir nostalgia del orden anterior.

Lo cierto es que la idea de civilizaciones compactas y homogéneas no se verifica en la realidad. Éstas no constituyen realidades cerradas, destinadas a enfrentarse fatalmente unas a otras.

La historia nos muestra una y mil veces que las civilizaciones son permeables, porosas, cambiantes, propensas al mestizaje cultural, al sincretismo; al traspaso de las costumbres, a las reinterpretaciones y las reapropiaciones entre aspectos de una y otra cultura, que hacen de ellas algo abierto en mayor o menor medida.

Tiene razón Jean Duvignaud cuando se pregunta si son silenciosos los pueblos dominados, si reciben pasivamente la cultura del vencedor:

Ávidos como están de ampararse de las herramientas del vencedor corrompen la imagen que éste se hace de sí mismo, semillas microscópicas invaden y modifican la conciencia del señor. ¿Es que los esclavos griegos, arrancados de su patria, a menudo también griega, no introdujeron pedazo a pedazo leyendas venidas de los confines del Asia, de los Balcanes, que se mezclaron con los mitos en base a los cuales más tarde los poetas harían el teatro? ¿Y a la vez Grecia vencida por Roma no aportará con sus aventureros, sus viajeros y sus comerciantes las semillas que germinarán en la cultura latina? ${ }^{4}$

En verdad los conflictos de ayer y de hoy, incluso aquellos que se revisten de portadores de un reclamo identitario o, al contrario, de una

${ }^{4}$ Jean Duvignaud, "La contamination", en Le métis culturel. Internationale de l'imaginaire 1 (1994). 
responsabilidad universalista, se mezclan siempre con razones menos ideales, con cosas muy concretas como el poder, la conquista territorial o el dominio económico.

El argumento civilizacional, cultural, identitario o religioso es muchas veces la cobertura emocional necesaria para la movilización bélica, aquello que le otorga en cierta medida "sus cartas de nobleza". Por lo demás, algunas de las guerras más cruentas, de las acciones criminales más sangrientas tienen lugar al interior de un mismo ámbito cultural, vale decir, de un mismo espacio civilizacional.

En buena parte lo que sucede hoy es que, habiendo perdido fuerza el gigantesco eje ideológico de la Guerra Fría, la razón cultural que estaba subsumida por la razón política adquiere una fuerte presencia y reemplaza en cierta medida a esta última como lógica explicativa y movilizadora del conflicto.

La expresión más dura y conflictiva actual se da a través de lo que he llamado "construcciones identitarias antimodernas", cuyo discurso plantea una eterna repetición de una tradición particular, negando todo valor al pensamiento del otro. Lo curioso es que no siempre se trata de un retorno a la tradición, sino - muchas veces - de una reconstrucción de esa tradición en clave fundamentalista, con el fin de usarla contra una modernidad que se asimila a lo occidental. El pasado que se invoca $y$ en el que el discurso se atrinchera es muchas veces inventado, a lo menos parcialmente.

Al otro extremo de esta concepción están quienes en Occidente se consideran cruzados de una modernidad que asimilan a su propia versión de lo moderno, cuando no a sus intereses, y son capaces de invadir territorios, levantando nobles banderas de transferencias democráticas que apenas recubren sus ansias de obtener ventajas económicas o geopolíticas. Esos mismos discursos son capaces de agregar también invocaciones a un mandato divino, como sucedió en la invasión de Irak, donde cada quien actuaba en nombre de Dios, que curiosamente resultaba ser el mismo, el del libro.

Lo real es que las tensiones entre lo identitario y lo universal cruzan con distinta dimensiones y peso a todas las regiones del mundo, y constituyen un aspecto muy visible de la fase más negativa del proceso de globalización. Al interior de lo que conocemos por Occidente, también se manifiesta en expresiones xenófobas y nacionalistas laicas, que pueden combinarse o no con aspectos religiosos. 
Es en Europa, no en otro lugar, donde se vivió una guerra sangrienta con todos estos componentes. Fue en la ex Yugoslavia, después de la Guerra Fría. Y si no queremos ir tan lejos, basta recordar que hoy existe allí una fuerte tensión con el fenómeno migratorio, así como entre Rusia y una Ucrania postsoviética profundamente erosionada.

Sin embargo, el centro de la atención está puesto actualmente en la versión más dura y guerrera del islamismo.

Se ha señalado que sus principales raíces se encuentran en los avatares de la historia, que han contribuido a que la versión más dogmática e incapaz de dialogar con una modernidad normativa tenga, en los países islámicos, una fuerza y una capacidad de acción tan grande.

En todas las religiones, con rarísimas excepciones, han existido interpretaciones guerreras, de un fundamentalismo agresivo que ha generado en momentos de la historia guerras y masacres. Pero de una u otra manera han ido prevaleciendo en ellas recorridos que las han llevado con mayor o menor dificultades a un diálogo posible, y a constituirse en parte de esa modernidad normativa que valora el Estado laico, la democracia y el pluralismo político.

La fortaleza de la versión guerrera del Islam, el islamismo, parecería obedecer en gran medida a una larga historia de subyugación y dominación colonial, que marcó durante siglos el desarrollo de la cultura árabe a partir de la derrota de su expansión territorial en el siglo XV.

Hasta entonces su desarrollo no era sólo comparable al del Occidente cristiano, sino que en algunos aspectos incluso era superior. Recordemos que mientras en Europa existía la caza de brujas y la Inquisición, en la España del siglo XII, el califato de Córdoba era tan tolerante que podían convivir sin problemas Maimónides e Ibn Arabi, vale decir, el máximo filósofo medieval hebreo y el máximo filósofo medieval islámico.

Sólo desde el siglo XV se consolidó una superioridad económica científica y militar de Occidente cristiano que, de la mano con el renacimiento cultural, cristalizaría en la alta modernidad y se convertiría en una fuerza dominante hasta el fenómeno colonial en el siglo XX. Tal proceso se acompañaría de un sentimiento de superioridad civilizatoria a partir del refinamiento de la vida cortesana, los modales, las prohibiciones y las normas de comportamiento social que tan bien describe Norbert Elias. ${ }^{5}$

${ }^{5}$ Norbert Elias, El proceso de civilización. Investigaciones sociogenéticas y psicogenéticas (México: Fondo de Cultura Económica, 1968). 
Pero no sólo vino de Europa la dominación al mundo árabe, también la ejerció el Imperio Otomano, con el que compartía la fe islámica. Fueron siglos de humillación que no concluyeron con una guerra santa sino con movimientos nacionales modernos, partidarios de un Islam abierto al mundo y de Estados laicos, los que se fortalecieron y salieron de la dominación colonial usando los propios instrumentos de los colonizadores, a través de procesos de rebelión y negociación.

Ese renacimiento árabe de mediados del siglo $\mathrm{XX}$, lejano a una interpretación guerrera del Islam, derivó sin embargo en regímenes autoritarios y corruptos que dejaron a sus pueblos a la deriva, disponibles para aceptar — no sólo en el mundo árabe, sino que también en el amplio mundo islámico - formas desesperadas de identidad y orgullo, canalizadas por grupos políticos capaces de popularizar a través de la modernidad instrumental las versiones más intolerantes del Islam, personificando en Occidente el mal absoluto, el Gran Satán.

Esta versión de identitarismo cerrado parte de un primer error, que es confundir el rol histórico del pensamiento de Occidente en la idea del universalismo con una visión excluyente. Al respecto, Amartya Sen nos recuerda que "Europa habría sido muy pobre - económica, cultural y científicamente - si hubiese opuesto resistencia a la globalización de las matemáticas, de las ciencias y de las tecnologías provenientes de China, India, Persia y el mundo árabe del segundo milenio". 6

Dante Alighieri, no sería el Dante, al igual que no poco de sus contemporáneos, si, como dice Braudel, "no se hubiera dejado contaminar por los autores árabes, cuya superioridad científica y filosófica los imponía como modelos". 7

Elementos de vida democrática existieron en numerosas regiones de India y elementos del Estado moderno en China. Pero, claro, el trayecto de lo universal tiene su tronco principal en Occidente, aun cuando, seamos claros, de un Occidente excéntrico, a lo menos geográficamente: podríamos decir del suroriente de Occidente, pues tiene su raíz en la antigua Grecia en relación al valor universal de la razón y la lógica; en Roma en relación al cuadro jurídico y la ciudadanía, y en el

\footnotetext{
${ }^{6}$ Amartya Sen, Identitá e violenza (Bari: La Terza, 2008).

${ }^{7}$ Fernand Braudel, Le modéle italien (París: Fayard, 1994).
} 
cristianismo, sobre todo a través de la promesa paulina que plantea la salvación de todos sin distinción. ${ }^{8}$

El recorrido de la idea de lo universal - para llegar a su punto más álgido con los filósofos de la Ilustración, con el pensamiento de Immanuel Kant como constructor de la modernidad junto a Montesquieu, Rousseau, Voltaire, Condorcet, Jefferson, Locke, Hegel, Adam Smith y Tocqueville, entre otros, y los procesos políticos fundacionales de la Revolución Francesa, la Reforma Inglesa y la fundación de Estados Unidos de América- hubo de realizar antes un largo y pedregoso camino: el del Renacimiento, la Reforma, las guerras de religiones, la derrota del absolutismo, teniendo como bastión intelectual en su formación el pensamiento tolerante de Montaigne, Descartes, Erasmo y Spinoza, así como el de quienes generaron la autonomía relativa y desencantada del pensamiento político: Maquiavelo, Tomás Moro y Hobbes. El vínculo entre la idea de lo universal y la historia de Occidente fue cualquier cosa menos un largo río tranquilo. Su avance intelectual y político estuvo en tensión permanente con una historia dura, sangrienta, que no ha terminado y que ha sido escenario de esclavitud, colonialismo, racismo, discriminación, estructuras patriarcales, dictaduras, totalitarismos y genocidios.

Para no ilusionarnos con una universalidad ahistórica y marmórea, Norberto Bobbio nos recuerda que la mismísima "Declaración Universal de los Derechos Humanos" de 1948 "representa la conciencia histórica que la humanidad tiene de sus propios valores fundamentales en la segunda mitad del siglo XX, pero sus tablas no han sido esculpidas de una vez y para siempre". 9

Recordemos que la interpretación de esas reglas fue muy controvertida durante la Guerra Fría y no sólo por la superpotencia que se nos viene a la mente, sino por ambas.

Terminada la Guerra Fría las cosas no cambiaron mucho. En la Conferencia Mundial de las Naciones Unidas sobre Derechos Humanos celebrada en Viena en 1993, China y algunos países árabes se opusieron en nombre de su identidad cultural a la universalidad de los derechos

8 Ver François Jullien, De l'universel, de l'uniforme, du commun et du dialogue entre les cultures (París: Fayard, 2008).

${ }^{9}$ Citado en Ernesto Ottone, "Norberto Bobbio por Agustín Squella: un libro necesario", Estudios Públicos 99 (2005). 
que atañen a los individuos. Ni hablar de las conferencias sobre la mujer y de población, en las que han chocado con estruendo diferentes lecturas del universalismo.

¿Qué camino seguir entonces en el siglo XXI para lograr niveles más altos de exigibilidad de conductas que nos conduzcan a una globalización más cerca de la paz que de la violencia? ¿Cómo combinar valores universales con identidades culturales?

Tal conciliación es imposible si consideramos lo universal como sinónimo de una cultura superior inmodificable, ajena al tiempo y al espacio, ya sea porque su origen es transcendente o su superioridad, implacable y debe ser trasladada al otro como un todo, entrando en su historia a la fuerza, si así se requiere.

Es imposible también si se entiende la identidad cultural como algo estático, invariable, que se encarna en formas de convivencia excluyentes, en la repetición infinita de una singularidad exacerbada que es más dura que su propia historia, y que pretende adscribir a las personas a una pertenencia única que abjura de la diversidad, para degenerar en un comunitarismo sin ventanas.

Así considerados, efectivamente son conceptos llamados al enfrentamiento.

Para encontrar caminos que nos conduzcan a evitar la fatalidad de ese conflicto es necesario acudir a conceptos, más "débiles" en el sentido que los entiende Vattimo, más blandos, que permitan en quienes los hacen suyos inspiraciones y convicciones muy distintas entre sí.

En vez de una identidad cultural cerrada, que puede ser fruto más de una construcción que de la tradición, resulta preferible una identidad cultural abierta a la contaminación del otro, capaz de conservar tradiciones, costumbres y valores, pero también de perderlas o transformarlas. No siempre es malo perder tradiciones. No veo qué pueda tener de positivo la subordinación de la mujer y la existencia de las castas, por ejemplo.

Las identidades culturales abiertas, aquéllas capaces de aceptar el mestizaje, pueden no sólo convivir, sino conformar y enriquecer un universalismo histórico y cambiante. Una identidad así concebida debe reconocer la pertenencia múltiple y no unívoca del individuo, aquella que nos señala Amartya Sen: 


\begin{abstract}
Existe una gran cantidad de categorías a las cuales pertenecemos simultáneamente. Yo puedo ser al mismo tiempo asiático, ciudadano de la India, bengalí con ancestros en Bangladesh, residente en los Estados Unidos y Gran Bretaña, economista, filósofo en mis ratos libres, escritor, conocedor del sánscrito, laico, heterosexual y defensor de los gays y las lesbianas, con un estilo de vida no religioso, de familia hinduista no Brahman, que no cree en la vida después de la muerte y tampoco, en caso de que quieran saberlo, en una vida antes de la vida. ${ }^{10}$
\end{abstract}

Pasando a una dimensión más particular y concreta, resultan curiosos algunos aspectos identitarios que parecen no tener la pureza de origen que a veces uno cree.

El sociólogo inglés Sami Zubaida ha demostrado que los restaurantes indios son una invención de los bengalíes que llegaron a vivir a Londres, al igual que los platos que son los embajadores gastronómicos de la comida india. En el marco de la globalización tales restaurantes han sido exportados a la India, lo que ha estimulado a los hogares indios a cocinar su comida de acuerdo a las invenciones londinenses. Hoy se puede probar comida "india" incluso en India, lo que confirma lo mucho que tiene de mito la pureza de los orígenes.

La contraparte de esta identidad abierta se encuentra en una nueva aproximación del universalismo, que parte por decirlo así más desde abajo que desde arriba, aun cuando sin perder su derivación fundamental del pensamiento kantiano.

El sociólogo alemán Ulrich Beck rescató con audacia el concepto de cosmopolitismo, siguiendo a Kant como sinónimo de universalismo, para proponer un proceso de cosmopolitización capaz de asumir la diversidad histórica, buscando el melange de lo local, lo provincial, lo nacional, lo étnico y lo religioso, para decir que "la cosmopolitización sin provincialismo queda vacía y que el provincialismo sin cosmopolitización queda ciego". 11

Se trata entonces de un universalismo histórico, que se modifica en el tiempo, compuesto, que se aleja de un universalismo abstracto.

\footnotetext{
${ }^{10}$ Sen, Identitá e violenza.

${ }^{11}$ Ulrich Beck, Cosmopolitan Vision (Cambridge: Polity Press, 2006).
} 
En base a estas dos visiones de identidad y universalismo puede construirse el concepto que he llamado "acumulación civilizatoria". Entiendo por tal un conjunto de prácticas y valores reconocidos progresiva y transitoriamente como compartidos y compartibles, no porque respondan a la superioridad de una matriz cultural, sino porque la práctica histórica muestra que contribuyen a una convivencia pacífica, a relaciones más horizontales y justas, en las que se respetan las singularidades de los grupos pero a partir del respeto a la autonomía individual y de una dignidad inseparable de las personas.

Sin duda que ello puede aparecer algo ingenuo frente al mundo del poder y de los intereses económicos, que son decisivos en la estructuración de los asuntos globales. Pero yo no pretendo que este concepto reemplace la dureza del mundo de los intereses económicos y políticos. Esos intereses serán siempre determinantes. Pero un concepto de este tipo puede al menos contribuir a "dulcificar las costumbres", como señalaba Montesquieu respecto al comercio, ayudar a descorrer los velos de nobleza con los que la rudeza política y económica cubren sus acciones, aislar a los pensamientos fanáticos portadores de verdades indiscutibles. Y tengo la convicción de que puede hacerle sentido a la mayoría de la gente, independientemente del espacio cultural en el que estén insertos.

Quisiera señalar que nuestra región, América Latina, tendría mucho que ganar con una concepción de este tipo como marca de la convivencia global. Nuestra historia no es ajena a dominaciones étnicas crueles, a la negación del otro, a discriminaciones, a una esclavitud extendida y larga en el tiempo, pero al mismo tiempo poseemos, quizás como nadie, un fuerte mestizaje, un valioso sincretismo cultural, la ventaja histórica de independencias tempranas y la creación de Estados laicos en los cuales, si bien subsistió el patrimonialismo particularista, tuvieron un temprano reconocimiento las ideas universalistas de la Ilustración. Desde hace muchos años que carecemos por completo de versiones guerreras de la religión; más bien, la religión es actualmente un factor de paz.

Nuestra histórica fragilidad democrática nos ha hecho tomarnos muy en serio, por otra parte, el tema de los derechos humanos. En los últimos decenios de manera no lineal pero importante, América Latina ha hecho también un aprendizaje formidable de las bondades de la solu- 
ción pacífica de los conflictos. Esos elementos, que pueden ser una contribución regional a una cosmopolitización diversificada y no violenta, se deben cuidar como un bien precioso. Esta reflexión vale plenamente para nuestro Chile de hoy, para su vida interna, así como para su inserción internacional y rol en el mundo.

Hace ya algunos años el inolvidable escritor mexicano Carlos Fuentes dio una conferencia en La Moneda, y ante una pregunta cargada de identitarismo cerrado respondió:

La globalización es como Jano, la divinidad romana que tiene una cara buena y una cara mala.

Una cara mala es la cantidad de basura informativa que se nos arroja. Pero eso pone a prueba nuestra resistencia cultural. Ella no depende del aislamiento, no depende de decir "yo soy puro mexicano no tengo nada de indio ni de español". No quiere decir eso. Quiere decir que estamos abiertos a la multitud de culturas que nos han formado, trátese de la filosofía griega, del Renacimiento, de las culturas indígenas, de las culturas africanas, de todo lo que ha hecho la cultura de la América indo-afro-europea. Yo no tengo miedo porque sé que sabemos separar la basura de los buenos contenidos. Pertenezco a una generación de escritores latinoamericanos que no habríamos escrito nada sin William Faulkner, sin John Dos Passos. ¿Cómo vamos a negar la enorme potencia cultural de la música de Gershwin, del buen cine de Hollywood, del teatro de Europa, de Eugene O'Neill o de Arthur Miller? ¿Vamos a negar todo eso en nombre de nuestra pureza cultural latinoamericana, de nuestra virginidad cultural? No. ${ }^{12}$

Y llevado por el entusiasmo, concluyó con un arranque, es cierto, muy poco académico, y quizás más mexicano que cosmopolita, exclamando a voz en cuello: "Las vírgenes a los burdeles, nosotros a la calle". EP

${ }^{12}$ Carlos Fuentes, "Transformaciones culturales", conferencia en Palacio de La Moneda, Santiago de Chile, 2004. Se puede leer publicada en Carlos Fuentes, "Transformaciones culturales y una agenda latinoamericana", Cuadernos del Foro de Valparaíso VII (sin fecha), 63 (https://issuu.com/miradordelaglobalizacion/docs/ cuaderno_7foro). 